\title{
O que foi discutido e pesquisado no Grupo de Discussão e Pesquisa em Educação Ambiental e contexto escolar (GDP) do EPEA-2019?
}

\author{
What was discussed and researched in the Environmental Education Discussion and \\ Research Group and school contexto (GDP) of EPEA-2019?
}

\section{¿Qué se discutió e investigó en el Grupo de Discusión e Investigación sobre Educación Ambiental y el contexto escolar (GDP) de EPEA-2019?}

\author{
Patrícia Domingos ${ }^{1}$ \\ Silvana do Nascimento Silva ${ }^{2}$
}

\begin{abstract}
Resumo
O texto traz a análise dos artigos do GDP - EA e contexto escolar do EPEA/2019 e investiga as vozes dos partícipes, sujeitos histórico-sociais que labutam nas escolas e universidades públicas brasileiras. A pesquisa foi qualitativa, emergindo, da análise textual discursiva, as seguintes categorias: 1) características dos artigos: a) identificação: as instituições dos pesquisadores são das regiões Sul, Sudeste, Nordeste e Norte do Brasil, b) local, partícipes e objetos pesquisados: locais mais pesquisados são escolas públicas e os partícipes são estudantes e professores, c) natureza e tipo de pesquisa: abordagem qualitativa do tipo teórica, descritiva, pesquisa-ação... d) coleta de dados: entrevistas, questionários, observações... e) análise de dados: análise de conteúdo, análise textual discursiva, análise de discurso... Os aspectos principais, oriundos das vozes dos partícipes, nas discussões do GDP foram: a) relação universidade-escola e b) desenvolvimento da EA Crítica na escola.
\end{abstract}

Palavras-chave: Relações pesquisador-pesquisados no contexto escolar. Relações universidade-escola. Educação ambiental crítica na escola.

\begin{abstract}
The text brings the analysis of the articles of GDP - EE and school context of EPEA/2019, and investigates the voices of the participants, historical and social subjects who work in Brazilian public schools and universities. The research was qualitative, the following categories emerged from the textual discursive analysis: 1) characteristics of the articles: a) identification: the institutions of the researchers are from the South, Southeast, Northeast and North regions of Brazil, b) local, participants and objects researched: most researched places are public schools and the participants are students and teachers, c) nature and type of research: qualitative approach, theoretical, descriptive, action research... d) data collection: interviews, questionnaires, observations... e) data analysis: content analysis, textual discourse analysis, discourse analysis... The main aspects, arising from the voices of the participants, in the GDP discussions were: a) university-school relationship and b) development of Critical EE at school.
\end{abstract}

Keywords: Researcher-researched relations in the school context. University-school relations. Critical environmental education at school.

\footnotetext{
${ }^{1}$ Bióloga. Doutora em Biotecnologia Vegetal/UFRJ. Professora no Programa de Pós-Graduação Mestrado Profissional em Ensino de Biologia em Rede Nacional - ProfBio/UERJ e no Programa de Pós-Graduação em Biologia Vegetal/UERJ. Coordenadora do Laboratório de Ficologia e Educação Ambiental (LAFEA/IBRAG/DBV/UERJ). E-mail: patdomingos.uerj@gmail.com

${ }^{2}$ Bióloga. Doutora em Ensino, Filosofia e História das Ciências/UFBA.l. Professora no Programa de PósGraduação em Educação Científica e Formação de Professores/Uesb. Coordenadora do Grupo de Pesquisa em Educação Ambiental e Formação de Professores/GPEA-FP. Coordenadora do Laboratório de Ensino de Biologia/UESB. Email: siluesb@ hotmail.com
} 


\section{Resumen}

El texto trae el análisis de los artículos de GDP - EA y contexto escolar de EPEA/2019 e investiga las voces de los participantes, sujetos históricos y sociales que trabajan en escuelas públicas y universidades brasileñas. La investigación fue cualitativa, y las siguientes categorías surgieron del análisis discursivo textual: 1) características de los artículos: a) identificación: las instituciones de los investigadore s son del Sur, Sureste, Noreste y Norte de Brasil, b) ubicación, participantes y objetos investigados: los lugares más investigados son las escuelas públicas y los participantes son estudiantes y profesores, c) naturaleza y tipo de investigación: enfoque cualitativo de la investigación teórica, descriptiva, de acción ... d) recopilación de datos: entrevistas, cuestionarios, observaciones... e) análisis de datos: análisis de contenido, análisis de discurso textual, análisis de discurso... Los principales aspectos, derivados de las voces de los participantes, en las discusiones sobre el GDP fueron: a) relación universidad-escuela y b) desarrollo de EA crítica en la escuela.

Palabras clave: Relaciones investigador-investigados en el contexto escolar. Relaciones universidad-escuela. Educación ambiental crítica en la escuela.

\section{Introdução}

A Educação Ambiental brasileira é um campo consolidado que, ao longo do tempo, tem mostrado o seu caráter dinâmico na produção de conhecimentos (SILVA, 2019). Esses conhecimentos são produzidos, em sua maioria, por pesquisadores de instituições públicas, como universidades estaduais e federais. Frequentemente, as produções são disponibilizadas no formato de dissertações e teses que, via de regra, se desmembram em artigos científicos. Estes são vinculados, por exemplo, em periódicos nacionais e internacionais, como também em atas de eventos científicos.

O foco principal deste artigo é abordar o evento Encontro Pesquisa em Educação Ambiental (EPEA) como ponto de partida para discussões e pesquisas nele materializados. Aqui, é apresentado um recorte pontual do EPEA de 2019, em sua décima edição, que ocorreu em Sergipe, no período de 01 a 04 de setembro. O evento tem se consolidado como uma ação colaborativa de diversos grupos de pesquisas em Educação Ambiental no Brasil (SILVA; DOMINGOS, 2019).

Em tempos de silenciamento e tentativa de apagamento de políticas públicas no campo da Educação Ambiental brasileira, o EPEA-2019 veio fortalecer os pesquisadores, tanto docentes como discentes, na luta em prol da resistência e insurgência de possibilidades profícuas no âmbito socioambiental. Destaca-se, nesse esforço, a busca por transformar a realidade atual, advertida por Loureiro (2019, p.36), na qual: "há atualmente um conjunto enorme de dados, gráficos, tabelas, e séries históricas com informações sobre a inquietante velocidade em que estamos envenenando nossos corpos, destruindo rios, ecossistemas e biomas... matando pessoas de fome...".

Nessa direção, o Grupo de Discussão e Pesquisa (GDP) tem se constituído como espaço democrático que possibilita a produção de pesquisa, além de promover discussões entre os pares, na tentativa de compreender e transformar a realidade hegemônica que o sistema capitalista, a partir dos seus grupos dominantes, vem impondo à população brasileira. Reconhecemos a necessidade de discutir o modelo de desenvolvimento gerador da desigualdade e de ameaça à vida, como um todo, modelo esse que "traz também uma defesa do capitalismo e do crescimento econômico como solução para a pobreza, aceitando a destruição ambiental como sua consequência" (LOUREIRO, 2019, p. 109).

No EPEA os GDPs são organizados de forma a constituir espaços específicos que fomentem debates sobre movimentos sociais e justiça ambiental; contexto escolar; contextos não escolares; questões epistemológicas; questões metodológicas; culturas; formação de educadores/ professores, e políticas públicas, tornando-se em si sítios para interessantes pesquisas (SILVA; DOMINGOS, 2019). 
Nesse sentido, as autoras deste artigo, que se constituíram em 2019 como coordenadoras do GDP EA e contexto escolar, partiram do objetivo de analisar os artigos aprovados e também do escopo de investigar as vozes dos partícipes de tal GDP, constituído por sujeitos histórico-sociais que labutam nas escolas e universidades públicas brasileiras.

\section{Referencial Teórico}

O avanço e expansão crescentes do capitalismo sobre novos territórios conduzem um processo de acumulação e concentração de renda nas mãos de poucos, o que promove a exclusão de um número cada vez maior de pessoas. Esse processo também gera um aprofundamento da destruição da natureza e das desigualdades, em todas as instâncias e regiões do planeta. Assim, a luta por direitos, por igualdade e justiça têm se intensificado.

A luta por justiça socioambiental (direitos, igualdade, sustentabilidade...) visa romper o ciclo da desigualdade, a partir de práticas sociais nas quais ações sustentáveis possam ser implementadas para o bem da coletividade, sem perder de vista como se estruturam as classes sociais que, por sua vez, formam a sociedade contemporânea (SILVA, 2019).

Nessa busca incessante por justiça socioambiental via ações sustentáveis para solucionar os problemas socioambientais, a Educação Ambiental (EA) vem se destacando como um campo dinâmico, em constante produção de conhecimentos e ações (SILVA; ELHANI, 2014).

A EA como um processo político-social contempla os mais variados contextos, entre eles o formal, por exemplo, o escolar. Tozoni-Reis (2008) propõe a problematização do contexto local e a configuração dos sujeitos sociais, em toda sua complexidade, para a discussão na escola. Há, aqui, a possibilidade de encaminhar trabalhos e ações que, ao substituírem uma paisagem estática, ajustada e em equilíbrio, tragam uma realidade problematizada, explicitando os conflitos experienciados (SPALAOR; CONSENZA, 2017), e frequentemente silenciados, no território de proximidade da escola.

Assim, entendemos que a educação deva ter um papel primordial para a transformação dessa realidade, buscando explicitar as estruturas e as relações assimétricas de poder que dão sustentação ao contexto de injustiça socioambiental local (LAYRARGUES, 2002).

Nas práticas de contexto escolar, da mesma forma, a perspectiva que se deseja é

[...] a Educação Ambiental a partir do seu comprometimento com questões sociais, políticas, econômicas, ecológicas, culturais e ideológicas que se encontram intimamente relacionadas com degradações, injustiças e conflitos socioambientais, reconhecendo a relevância do papel desempenhado pelas escolas quanto ao desenvolvimento de práticas pedagógicas capazes de assumir o compromisso social de visibilizar omissões e dissimulações, evidenciar inércias e diligências e descortinar vulnerabilidades e destrutibilidades concernentes a injustiças socioambientais (COSENZA; KASSIADOU; SÁNCHEZ, 2014 apud SPALAOR; COSENZA, 2017, p.2).

A questão ambiental e a educação são, portanto, eminentemente políticas e implicam em construir, através da participação, referências necessárias à ação transformadora da sociedade, em prol de uma configuração que supere a desigualdade desta sociedade em que vivemos, desigualdade, esta, que determina as relações sociedade-natureza (TOZONI-REIS, 2006).

A educação ambiental que se proponha ações de explicitação das contradições produzidas pelo capitalismo, assume um papel central e estratégico na escola. Nesse sentido, como educação deve ser um ato político, para além de um ato de conhecimento (FREIRE, p. 10, 2018), a educação ambiental não tem caráter de neutralidade (LAYRARGUES, 2002), mas o de contribuir para o entendimento de lógicas hegemônicas, muitas vezes, pouco 
evidentes. Tais lógicas estão diretamente relacionadas com os problemas ambientais que, tratados numa perspectiva ingênua, não problematizada, pouco contribuem para sua superação efetiva.

Assim, reconhecendo Educação Ambiental como um termo polissêmico, entendemos, também, que em torno desse campo aglutinam-se os interessados em consagrar às questões ambientais um destaque para discussões atuais e de por vir da humanidade. Não é diferente na EA Escolar, onde diferentes entendimentos estão presentes, orientando metodologias e práticas diversas (ARAUJO; DOMINGOS, 2018).

A expectativa é que ações escolares reducionistas sobre a problemática socioambiental sejam superadas a fim de se evitarem práticas descontextualizadas da realidade da escola. Para Guimarães (2006), em tais práticas reside uma boa intenção de proposição, embora com atuação ingênua.

A Educação Ambiental Crítica, perspectiva em que nos alinhamos, é comprometida com ações que contribuam para desnaturalizar cenários de desigualdade e injustiças, e constitui-se numa opção plena de possibilidades, uma vez que busque aderência com questões vividas pelos sujeitos de aprendizagem. A Educação Ambiental Crítica, em síntese, busca pelo menos três situações pedagógicas:

[...] a) efetuar uma consistente análise da conjuntura complexa da realidade a fim de ter os fundamentos necessários para questionar os condicionantes sociais historicamente produzidos que implicam a reprodução social e geram a desigualdade e os conflitos ambientais; b) trabalhar a autonomia e a liberdade dos agentes sociais ante as relações de expropriação, opressão e dominação próprias da modernidade capitalista; c) implantar a transformação mais radical possível do padrão societário dominante, no qual se definem a situação de degradação intensiva da natureza e, em seu interior, da condição humana (LOUREIRO; LAYRARGUES, 2013 p. 64).

\section{Delineamento metodológico}

A pesquisa, quanto à caracterização dos artigos aceitos no GDP EA e contexto escolar e descrição das vozes dos partícipes de tal grupo de discussão, foi de natureza qualitativa (BOGDAN; BIKLEN, 2004) Essa abordagem permitiu a análise de forma exploratória, descritiva e minuciosa de todo processo investigativo.

A Análise Textual Discursiva (ATD) foi utilizada por possibilitar a compreensão dos significados construídos a partir da análise dos artigos e das falas dos participes do GDP (MORAES; GALIAZZI, 2011).

A ATD foi estruturada nas seguintes fases: a) desmontagem dos textos; b) unitarização, como um processo de agrupamento dos fragmentos textuais semelhantes; c) categorização das unidades de análise com sentidos próprios; d) construção do novo emergente sobre os fenômenos e discursos investigados (MORAES; GALIAZZI, 2011).

Da ATD emergiram duas categorias, a saber: 1) características dos artigos, e 2) vozes dos partícipes. Nesse sentido, a próxima seção apresenta os metatextos como desmembramento das categorias emergentes e suas interpretações à luz dos referenciais teórico-metodológicos utilizados.

\section{Resultados e Discussão}

\subsection{Características dos artigos}

A caracterização dos artigos submetidos ao Grupo de Discussão e Pesquisa EA e Contexto Escolar - EPEA, 2019, foi balizada a partir dos seguintes aspectos: a) identificação 
dos artigos, b) local, partícipes e objetos pesquisados, c) natureza e tipo de pesquisa, d) coleta de dados e e) análise de dados.

\subsubsection{Identificação dos artigos}

O GDP EA e contexto escolar obteve, no ano de 2019, o total de 38 artigos aprovados. As instituições às quais os pesquisadores são vinculados estão localizadas entre quatro regiões, a saber: Sul, Sudeste, Nordeste e Norte do Brasil (Quadro 1). No GDP EA e contexto escolar de 2017, também, as regiões Sudeste, Nordeste e Norte foram contempladas, juntamente com o centro-oeste (SILVA; DOMINGOS, 2019).

O Sudeste se destaca com o total de 21 artigos; destes, cinco estão vinculados a instituições de São Paulo (dois artigos são em parceria com outras instituições em Santa Catarina e Espírito Santo); cinco relacionados especificamente a pesquisadores do Espírito Santo; cinco direcionados especificamente a instituições de Minas Gerais e um em parceria com pesquisadora de Cuba. O Rio de Janeiro apresentou um total de seis artigos (um deles em parceria entre UERJ e UESB).

No contexto de pesquisa desenvolvida por pesquisadores de instituição do exterior, destaca-se a parceria entre Cuba e Brasil em um artigo. Artigos oriundos de outros países também foram encontrados no GDP EA e contexto escolar de 2017, com dois artigos de pesquisadores da Colômbia (SILVA; DOMINGOS, 2019).

Vale destacar que os pesquisadores, na sua grande maioria, estão vinculados a instituições públicas como institutos e universidades estaduais e federais. Em tempos sombrios, quando tais instituições vêm sendo sucateadas, desmanteladas e precarizadas, os pesquisadores seguem provando que a balbúrdia da Educação Ambiental em contexto escolar se faz necessária para a compreensão dos problemas socioambientais negligenciados pelo Estado (SILVA, 2019).

\begin{tabular}{|c|c|c|c|c|c|}
\hline País & Região & Estado & Instituição & Identificação & Total \\
\hline \multirow{16}{*}{ Brasil } & \multirow[t]{2}{*}{ Sul } & $\mathrm{RS}$ & UFRGS & 116 & \multirow[b]{2}{*}{2} \\
\hline & & PR & UNICESUMAR & 86 & \\
\hline & \multirow{14}{*}{ Sudeste } & \multirow[t]{2}{*}{ SP } & SEE/SP/UNESP & 185 & \multirow{14}{*}{21} \\
\hline & & & UNESP & 175 e 216 & \\
\hline & & SP/SC* & UFSCar/IFSC & 205 & \\
\hline & & SP/ES** & IFES/SEE-SP & 289 & \\
\hline & & \multirow[t]{5}{*}{ ES } & $\begin{array}{c}\text { UAB/ES } \\
\text { Inst Sapê Norte } \\
\text { UFES }\end{array}$ & 91 & \\
\hline & & & UFES & 101 & \\
\hline & & & $\begin{array}{l}\text { UFES/Inst. Sapê } \\
\text { Norte }\end{array}$ & 157 & \\
\hline & & & CEUNES/UFES & 122 & \\
\hline & & & $\begin{array}{l}\text { FVC } \\
\text { UFES }\end{array}$ & 158 & \\
\hline & & \multirow[t]{3}{*}{ MG } & UFOP & 190 & \\
\hline & & & UFJF & $\begin{array}{c}184,218 \mathrm{e} \\
244\end{array}$ & \\
\hline & & & UNIFEI & 219 & \\
\hline & & \multirow[t]{2}{*}{$\mathrm{RJ}$} & UERJ & 146 e 164 & \\
\hline & & & $\begin{array}{c}\text { SME/RJ } \\
\text { UERJ }\end{array}$ & 102 & \\
\hline
\end{tabular}




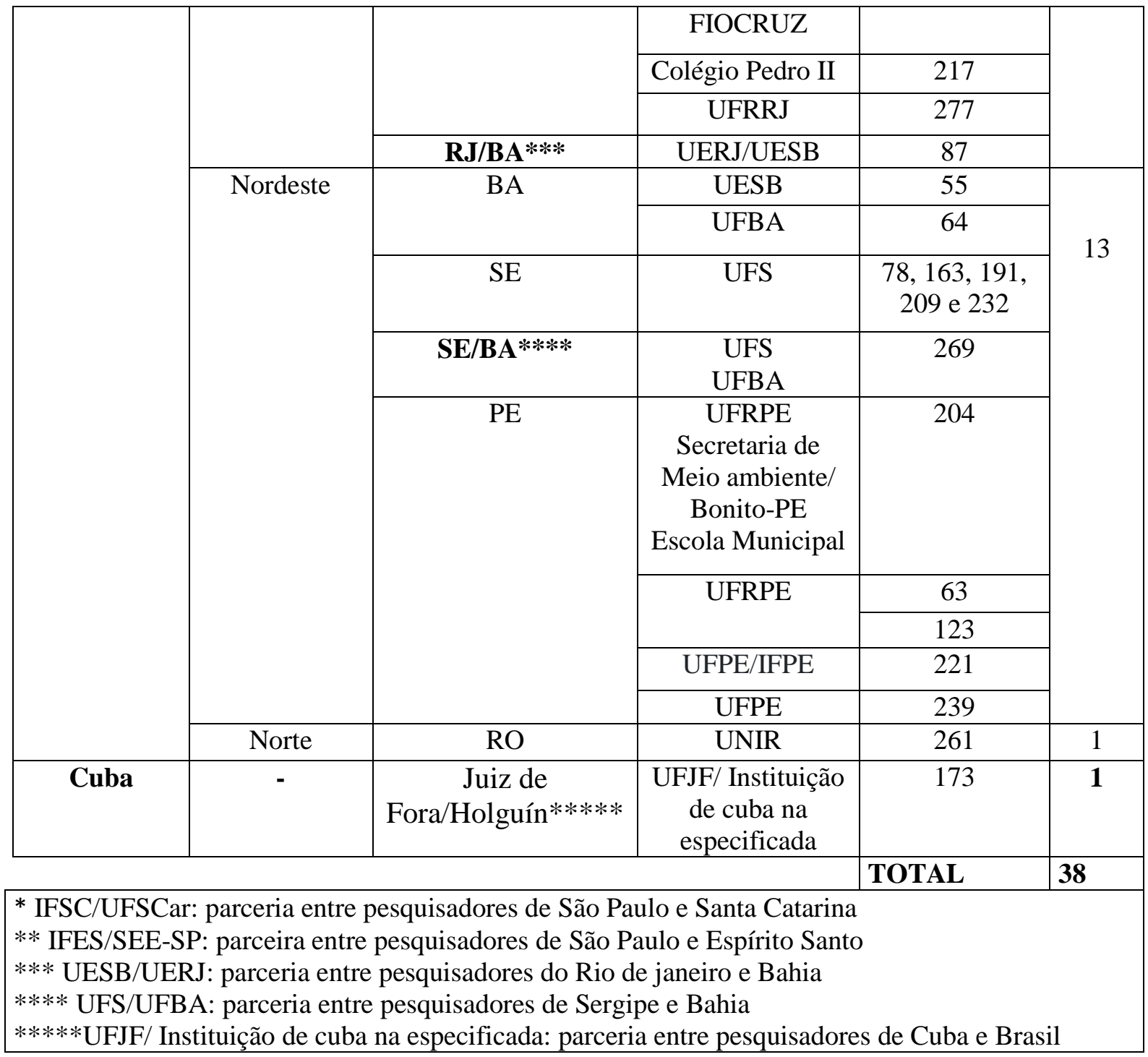

Quadro 1-Identificação dos artigos por país, região, instituição dos autores e numeração, conforme comissão científica do EPEA-2019 Fonte: Elaboração das autoras

\subsubsection{Local, partícipes e objetos pesquisados}

Em relação ao local do desenvolvimento das pesquisas relatadas nos artigos do GDP EA e contexto escolar, os artigos destacam como locais a escola pública/básica $(55,63,64$, 78, 91 101, 102, 116, 122, 157, 163, 164, 173, 184, 185, 204, 209, 216, 217, 221, 232, 244, 261, 269, 277 e 289), das redes federal, estadual e municipal que oferecem os ensinos fundamental, médio e técnico. Em quatro artigos não foi identificado o espaço onde a coleta de dados foi realizada. São eles: 87, 175, 190, 191, 205, 219 e 239.

Os artigos 123 e 146 relataram as universidades públicas como locais de desenvolvimento de pesquisa, enquanto os artigos 86 e 158 relataram universidades privadas.

$\mathrm{O}$ artigo 218 relata um curso formativo como local de pesquisa, mas não especifica em que instituição foi realizado.

Os sujeitos pesquisados citados no contexto escolar foram: gestores e coordenadores, professores da educação infantil, do ensino fundamental e médio; estudantes do ensino fundamental, médio, médio-técnico e superior, e comunidade local. Silva e Domingos (2019) postularam a necessidade de ainda se tornar imperativo nas pesquisas o estreitamento de laços entre comunidade escolar e local. 


\subsubsection{Natureza e tipo de pesquisa}

Quanto à natureza da pesquisa nos artigos do GDP EA e contexto escolar de 2019, impera, na maioria (trinta artigos), a abordagem qualitativa $(63,64,78,102,116,123,123$, 146, 157, 163, 164, 173, 175, 184, 185, 190, 191, 205, 209, 216, 217, 218, 219, 221, 239, 244, 261, 269, 277 e 289), sendo que sete artigos configuram a natureza quali-quantitativa $(55,87$, 91, 101, 158, 204 e 232) e apenas um é de abordagem quantitativa (86). Silva e Domingos (2019) também constataram a prevalência da pesquisa qualitativa nos artigos apresentados no GDP EA e contexto escolar de 2017.

O tipo de pesquisa, quando especificado, transita entre estudo de caso, observação participante, bibliográfica, teórica, diagnóstica, exploratória, descritiva e pesquisa-ação.

O estudo de caso compreende um caso ou vários casos particularizados, tendo como objeto de estudo um indivíduo, uma comunidade, uma escola, uma universidade, uma cultura (BARROS; LEHFELD, 2014).

A observação participante é descrita como parte do processo investigativo em que o pesquisador se integra ao grupo pesquisado. Vale destacar que existem outros tipos de observações utilizadas em pesquisas qualitativas, a saber: a) quanto à estruturação: assimétrica ou não estruturada e sistemática ou planejada; b) quanto ao número de observações: individual ou em equipe; c) quanto ao local: em campo e em laboratório; d) quanto à técnica de atuação na realidade: militante, e) quanto à participação: participante e não participante (BARROS; LEHFELD, 2014).

A pesquisa bibliográfica destaca-se pelo potencial em fornecer um panorama sobre as principais teorias disponíveis na literatura científica, muito aplicada no levantamento e revisão bibliográfica. Esse tipo de pesquisa, geralmente, é realizado em bancos de dissertações e teses, atas de eventos científicos, periódicos, jornais, revistas, utilizando, também, os acervos de bibliotecas físicas ou via internet (PIZZANI et al., 2012).

As pesquisas teóricas, como o próprio nome sugere, buscam analisar criticamente teorias, conceitos, ideologias, objetivando reconstruir ou aprimorar a própria teoria em estudo (BOGDAN; BIKLEN, 1994).

As pesquisas qualitativas também podem ser classificadas como exploratórias, que visam investigar ideias e teorias com base em hipóteses pré-estabelecidas; descritiva, por buscar descrever, de forma minuciosa, características e funções do objeto pesquisado, ou diagnóstica, que propõe um levantamento das características e funções do fenômeno investigado (BOGDAN; BIKLEN, 1994).

Por fim, a pesquisa-ação é aquela em que há uma integração entre pesquisador e sujeitos pesquisados, a fim de, coletivamente, desenvolver uma proposta investigativa colaborativa. Nesse sentido, o fator tempo é preponderante para o êxito da pesquisa proposta (GIL, 2008).

\subsubsection{Coleta de dados}

Os instrumentos de coleta de dados utilizados nos artigos foram entrevista (55, 64, 116, 122, 157, 164, 184, 209, 244 e 261), observações $(63,102,261$ e 277), diário de campo/de bordo (116 e 185), gravação de áudio (63, 122 e 217), vídeos (217 e 221), fotografias (217) questões (78, 218 e 289), questionário $(91,101,123,157,158,204,209$, 221, 232 e 277), documentos $(86,87,116,146,191,205,216$ e 219), relatos orais (164), produção textual (217), cartazes (218), discussão (269).

Os artigos em itálico são aqueles que apresentam mais de um tipo de instrumento de coleta de dados. Perfazendo um total de onze artigos, essa quantidade é superior ao que foi 
encontrado por Silva e Domingos (2019) no GDP EA e contexto escolar de 2017. A utilização de mais de um método de coleta de dados colabora com a eficácia sobre a interpretação do fenômeno pesquisado (TUZZO; BRAGA, 2016).

Cinco artigos não apresentaram caracterização quanto ao tipo de instrumento de coleta de dados utilizado, são eles: 163, 173, 175,190 e 239.

\subsubsection{Análise dos dados}

Quanto à análise dos dados, destacaram-se os seguintes tipos de referencial teóricometodológico: análise de conteúdo/categorização $(55,64,86,87,91,101,102,123,146,157$, $158,164,173,175,204$ e 219), análise de discurso (63, 122 e 191), análise crítica do discurso (184, 217 e 218), análise textual discursiva (205, 209 e 277), abordagem Bakhtiniana (185), abordagem histórico-social (216) abordagem vigotskyana (221). Ao mesmo tempo, foram encontrados artigos que não destacaram o tipo de referencial teórico-metodológico utilizado para análise dos dados, como os artigos 78,116, 163, 190, 232, 239, 244, 261, 269 e 289. Os resultados apontam a ausência de um método ou um referencial único a ser seguido na pesquisa em EA, pois "não há um padrão a adotar e nem um conjunto de conteúdos previamente elaborados" (LOUREIRO, 2019, p.57). O caminho teórico-metodológico se constitui pela problematização da realidade a ser pesquisada, preferencialmente na coletividade e dialogicidade com os sujeitos pesquisados (FREIRE, 2018).

Os pesquisadores reforçam que a Educação Ambiental ainda se destaca no contexto escolar por meios de projetos e ações (55), que pode agregar seu caráter inSURgente em feiras de ciências (64) e em horta escolar, como recurso pedagógico que possibilite a integração entre docentes e discentes no processo de ensino-aprendizagem, apontando a interdependência entre teoria-prática (78). Além disso, tais ações podem promover o contato das crianças/estudantes com o ambiente/natureza, como parte de um processo contrahegemônico (218). Contudo, ainda é preciso fortalecer temas e abordagens socioambientais face às ações do agronegócio, dialogando com a agroecologia, soberania alimentar e justiça ambiental (244).

Os resultados supracitados sobre os projetos e ações no contexto escolar, concordam com Santos e Silva (2018, p.3), quando advogam

[...] a necessidade de se discutir em sala de aula sobre as diversas temáticas que vêm contribuindo fortemente para o quadro societário atual de degradação do meio ambiente e da vida como um todo, baseado em uma sociedade que, além de estar dividida entre os detentores do poder e a classe oprimida, nega inclusive o direito à boa qualidade de vida, necessária ao ser humano.

Pesquisas apontam, também, os jogos cooperativos como potencializadores de metodologias ativas, por fomentar o aprendizado da educação ambiental crítica (146). A integração entre moradores da comunidade e escola é considerada salutar (87, 173 e 289) na tentativa de promoção da ambientalização curricular (116). Destaca-se, também, a escola como espaço democrático em que o currículo em EA tem possibilidades de construção coletiva (63). Acrescentamos que a essência da EA é promover a práxis libertadora, pois a partir da coletividade e diálogo inicia-se a busca do componente curricular (FREIRE, 2017).

Pesquisa em EA, voltada para o uso de recursos audiovisuais como ferramenta pedagógica, destaca o potencial para fomentar o protagonismo dos estudantes quanto à aquisição e produção de conhecimentos sobre conservação, importância ambiental, econômica, social e cultural de rios e/ou bacias hidrográficas (221). Ferramentas didáticopedagógicas que fomentam o protagonismo estudantil proporcionam "condições de 
enfrentamento dos problemas do seu cotidiano", voltadas principalmente para as questões socioambientais (SANTOS et al., 2018, p.237).

A pesquisa foi, também, pontuada como mecanismo de aproximação entre instituições públicas, na tentativa de estreitar os laços universidade-escola, via projetos de extensão, na busca do fortalecimento de sujeitos histórico-sociais autônomos, atuantes no campo da EA Crítica (164). Esse tipo de pesquisa precisa ser mais disseminado, primeiro pela representação social da parceria entre universidade e escola básica, que precisam fortalecer esse elo; segundo, por se tratar de uma pesquisa que envolve também a extensão, mais um elo que precisa ser reforçado, e terceiro, pela possibilidade de demarcar mais o território das instituições públicas de ensino, com esse fortalecimento (Escola-Universidade). Esses elos fortalecidos tornam-se estratégicos para o enfrentamento do crescimento de instituições privadas, que retiram financiamento público, destinado às escolas e universidade públicas (SILVA, 2019).

A percepção ambiental aparece como parte da interação indivíduo-ambiente por meio da percepção e cognição (175), onde se registram diferentes percepções dos sujeitos pesquisados, a depender do contexto analisado (204).

Em relação às representações dos sujeitos, os resultados dos artigos revelam tensões na predominância de compreensões conservacionistas e pragmáticas sobre o campo da EA (91, 158), nas quais temas como lixo mostram predominância da tendência naturalística /antropocêntrica, vinculada ao discurso ecológico (101). Isso nos remete a Layrargues (2002), ao sinalizar sobre trabalhos pedagógicos com resíduos sólidos (lixo) que recaem no chamado cinismo da reciclagem, em que o significado ideológico da reciclagem negligencia a discussão crítica sobre a produção e consumo, pautados na espoliação da natureza. Trata-se de uma perspectiva reducionista, que apela aos resultados, sem crítica à lógica capitalista, como a solução que basta.

Temas como extrativismo de minério (163), produção canavieira (209), mecanização, modernização agrícola, adubos, agrotóxicos e produção agrícola (216), importância de manguezais (232 e 269), unidades de conservação (277), injustiças ambientais (184), consumo, capitalismo e obsolescência programada (190), aquecimento global com base em aspectos socioeconômicos e políticos são de grande importância para um entendimento politizado sobre a problemática socioambiental (102). Entende-se que sua abordagem contribua para a compreensão da sustentabilidade e complexidade que permeiam a Educação Ambiental Crítica (123), com possibilidade de contextualização dos determinantes que engendram as relações Ciência-Tecnologia-Sociedade-Ambiente (191).

Tensões também são retratadas quanto às dificuldades do trabalho da Educação do campo (EC), em relação à sustentabilidade e agricultura familiar, atacada pelo modelo econômico vigente (122). O debate sobre problemas socioambientais da comunidade campesina, como temas geradores, potencializa as discussões das tensões socioambientais, ao promover a interface com a Educação Ambiental Crítica (157), pois "estabelece ricas reflexões acerca do modo de estar e agir do campesino, a compreensão de que esta discussão está intrinsecamente ligada ao espaço rural e às instituições que a compõe", gerando possíveis transformações da realidade pesquisada (AZEVEDO; SILVA, 2017, p. 9).

Investigação de cunho disciplinar, voltado para área da geografia, é sinalizada como promissora para construção de novos sentidos na relação ser humano-ambiente (185), ecoformação e ecocidadania (239), além de oportunizar o aprendizado da EA Crítica e transformadora com aporte interdisciplinar (217).

Pesquisa voltada para a análise de documentos oficiais como a Base Nacional Comum Currirular - BNCC, no que tange às áreas de Ciências e Geografia, destaca a ocorrência do culto a habilidades que privilegiam abordagens pragmáticas da EA (219). Pesquisas voltadas para a BNCC têm apontado o sequestro, silenciamento e apagamento da EA em tal documento (SILVA, 
2019). Nessa direção, o Estado visa um projeto de educação que cala o debate em torno dos problemas e crimes ambientais.

Um movimento inicial foi percebido quanto à investigação da EA Críticotransformadora, voltada para o campo de produção acadêmica da Educação profissional e tecnológica (205).

Por fim, pesquisa no contexto escolar, voltado para EA, argumenta sobre a veiculação de conhecimentos e valores éticos para formação cidadã (261).

Nessa perspectiva, identificam-se diferentes vertentes na EA escolar, embora com o reconhecimento de que o desejo dessas práticas seja a de uma ação transformadora, ou seja, nos trabalhos discutidos/apresentados, o docente pesquisado ou pesquisador se apresenta como um ator a favor da transformação social. No contexto mais recente de ataques aos direitos ambientais adquiridos e desmonte das estruturas institucionais que os garantiam, cabe buscar os pontos de intersecção e sinergia de tais ações, a fim de reconhecermos pontos de aderência em prol de uma atuação docente, na perspectiva da educação básica, mais coletiva e consistente.

\subsection{Vozes dos partícipes do GDP EA e contexto escolar em 2019}

As discussões de grupo (GDP) podem ser reconhecidas como componente central para o avanço das proposições de pesquisa em EA, como um todo e, em particular, para o contexto escolar. Trata-se, ainda, de uma particularidade do EPEA que, assim, se configura como um espaço de real possibilidade de integração horizontal e proposição coletiva.

Foram inscritos trabalhos no GDP EA e contexto escolar de quase todas as regiões do país, com exceção da região Norte. Esse cenário é importante a fim de considerar a representatividade parcial presente no EPEA e, principalmente, nas discussões do GDP. Futuramente, essas discussões poderão ter suas avaliações e proposições enriquecidas com a incorporação de aspectos da visão e vivências da diversidade regional do país.

Dentre os presentes, a pesquisa sobre o entendimento, percepção e sentido emprestados à EA escolar são as questões predominantes e a investigação sobre a prática docente também se revela como recorrente.

O GDP contou com a participação de pesquisadores de IES e professores da Educação Básica, o que promoveu uma troca de percepções e experiências que poderia se configurar, em certos momentos, como um diálogo entre os diferentes lugares, aqueles de onde procedem os discursos dos sujeitos pesquisadores e, igualmente, aqueles de onde partem as falas dos sujeitos pesquisados. Um diálogo que flui tornando-se tensão e complemento a fim de evidenciar os diferentes olhares e buscar um sentido que atenda às possibilidades e necessidades reais desse campo de pesquisa.

Com o desenvolvimento das discussões foi ficando clara a necessidade de ouvir as vozes dos partícipes daqueles GDP: professores da escola básica, gestores e pesquisadores presentes. Algumas questões apresentadas como importantes pelos últimos, destacam os limites de atividades em EA nas escolas a partir da dificuldade ou necessidade de articulação com os conteúdos curriculares que os professores devem trabalhar no ano letivo. A preocupação pode ser também reveladora de um entendimento na escola de uma EA que se estruture predominantemente por temas e conteúdos específicos, muitas vezes recorrentes como água, lixo, reciclagem, que necessitam de um momento certo para serem tratados. Uma visão que dê destaque à discussão sobre as relações ser humano-natureza, apontando para a superação desta dicotomia, talvez a questão central de EA (TREIN, 2012), encontraria mais possibilidades de ser desenvolvida, uma vez que pode se aproximar de todos os conteúdos programáticos. 
A mesma questão curricular é retomada a partir do ressurgimento de propostas da criação de uma disciplina de EA, que passaria a fazer parte da grade curricular das escolas. Essa questão, candente e clássica do campo, ainda merece atenção, tanto em face do envolvimento de seus integrantes, como diante de fatos novos que a recolocam numa esfera de revisão. A retomada da discussão entre a disciplinarização ou não de EA na escola básica encontrou uma recepção negativa por parte de docentes como um todo, considerando os presentes ao GDP.

A proposição recebeu críticas dos docentes das escolas, que apresentaram vários argumentos de ordem prática para sua implementação, como a formação necessária a um único profissional responsável pela disciplina, que garantisse sua perspectiva política da educação, a pouca disponibilidade de carga horária disponível, a partir de escola de três turnos, o que significa retirar o tempo de alguma disciplina já existente, o risco dos demais docentes se desresponsabilizarem da questão. Há que se considerar que a disciplinarização reforça uma compreensão fragmentada da realidade (COSTA; LOUREIRO, 2013) e termina conduzindo concepções mecanicistas e a busca de soluções técnicas e simplificadas, diante de problemas complexos.

Além disso, é do entendimento dos professores que a medida interrompe o diálogo entre professoras e professores diante de um tema complexo, reduzindo a possibilidade de práticas interdisciplinares na escola. Diante de problemas complexos como os socioambientais, concordamos com Rosa et al. (2017, p. 8), que a abordagem interdisciplinar é "essencial para a compreensão das questões ambientais a partir de uma perspectiva crítica".

Uma consideração a mais, que cabe reconhecer, diz respeito à perspectiva de que se o futuro professor atuar numa vertente conservadora, o mais provável, haveria tendência de inviabilizar uma nova perspectiva na escola que poderia, de outro modo, encontrar profissionais de outras disciplinas, abertos à reflexão de uma perspectiva crítica. Assim, representa a viabilidade de que a EA seja desenvolvida na escola a partir do conteúdo de qualquer disciplina, desde que haja um docente comprometido com a questão (FIGUEIRA et al., 2017).

Finalmente, apontam a necessidade de que se obtenha mais espaço das IES para a formação inicial em EA nos cursos de licenciaturas, entendendo que o PPP escolar é o espaço privilegiado para a construção de trabalhos, projetos e práticas em EA escolar.

A carência de material didático para EA Crítica foi destacada, o que remete à questão da dificuldade em se produzir tais materiais. A carência pode vir da dificuldade em tratar de problemas complexos, como os socioambientais, garantindo tanto uma abordagem estrutural, mas que aponte, também, as consequências comportamentais, individuais, mantendo uma coerência política.

Os conceitos desejáveis para uma EA Crítica, uma vez apreendidos, nem sempre são postos em prática de forma direta na escola. Muitas vezes, uma atividade se esgota de forma pouco crítica, entretanto, servirá para abrir a perspectiva para a atividade seguinte, que poderá aprofundar o entendimento.

A formulação de uma visão crítica e consistente passa pela aquisição qualificada de conhecimento e informação, a fim de não se tornar facilmente desmantelada. Esse processo educativo passa por diferentes momentos, nem todos terão garantidos alguns preceitos desejados em EA Crítica como a problematização da realidade, evidenciação de conflitos e contradições presentes no território, explicitação do quadro de injustiça socioambiental local e seus atores.

Entretanto, é fundamental que haja uma proposição na qual se construa um volume crescente de ferramentas de análise e de conhecimento para um objetivo final que, este sim, alcance um sentido crítico com um método que tenha trabalhado o diálogo, a dúvida, o desafio e a conclusão individual a partir de elaborações pessoais e coletivas de cenários 
complexos. Acreditamos que esse seja um caminho para o desenvolvimento da EA crítica nas escolas de nível fundamental e médio, adaptando-se às particularidades de cada situação.

Uma questão que deve ser ressaltada, diz respeito às limitações enfrentadas por professoras e professores da escola básica. Tais limitações incluem condições precárias de trabalho, como os contratos temporários que os tornam horistas à disposição dos sistemas públicos ou privados. Tais sistemas não se interessam por corrigir falhas de atendimento, uma vez que a exploração do trabalho docente é compensadora. Há, ainda, limites institucionais, onde, uma vez que as aulas sejam realizadas, não há necessidade de cumprir exigências e custos trabalhistas, garantindo elevação de ganhos ou lucros. O triste é ver que os docentes aceitam essa relação de trabalho, onde, muitas vezes em casa, são chamados a qualquer momento para cumprir a falta de um professor de qualquer disciplina, onde for necessário, como já se observa.

Ainda, a precarização das relações de trabalho no contexto educacional gera a redução da capacidade de enfrentamento à entrada nas escolas de perspectivas conservadoras e apaziguadoras de conflitos socioambientais, através de projetos externos de EA. Tais noções entram com força nas escolas, acompanhadas de materiais e oferta de premiação para professores, alunos e escolas, como o caso do agronegócio (LAMOSA, 2017). Longe de ser neutra, traz uma forte articulação pela aceitação dos problemas que produz, com a justificativa da geração do emprego e um pseudodesenvolvimento, que ao final, termina em benefício de poucos e prejuízo para muitos e para o ambiente.

Torna-se primordial a discussão do conceito de desenvolvimento. Esse é um ponto central na discussão da EA e deve estar presente nas escolas, à luz das diversas disciplinas que revelem aderência e pertinência ao tema, como geografia, biologia, história, e outras que tenham aproximação.

\subsection{Relações Universidade - Escola}

Uma questão que surgiu da discussão do primeiro dia de GDP, e que foi repercutida no grupo, partiu do questionamento: a produção de conhecimento de EA comprometida politicamente está a serviço de quem?

A questão surgiu da demanda das escolas por uma pesquisa mais comprometida com sua realidade e que retorne como conhecimento para o avanço de suas práticas individuais e coletivas.

Destacou-se o entendimento de que a categorização das práticas de EA, sobretudo nas macrotendências propostas por Layrargues e Lima (2014) ganhou grande dimensão e está presente em muitas pesquisas realizadas nas escolas, frequentemente com caráter prescritivo, mas que não contribui para o avanço daquela prática local. Professores defendem a pesquisa de intervenção, colaboradora, formadora e coletiva.

A consideração é que os mais de dez anos de classificação da EA escolar é algo deslocado de sentido, uma vez que a resposta já é previamente conhecida, ou seja, é muito pouco provável que a escola e seus docentes elaborem isoladamente uma proposta contrahegemônica (ROSA et al., 2017) de EA escolar. A academia foi considerada prescritiva, pois há várias orientações sobre o como deve ser, mas, na prática, a oferta de instrumentos didáticos é escassa. Decorrente disso, os professores são culpabilizados por uma prática de EA ingênua e/ou naturalista, sem receberem um retorno para o avanço teórico-metodológico.

Foram discutidos elementos que contribuam para o aprimoramento e rigor da pesquisa. Nesse sentido, destacaram-se como orientação, em geral, as análises que evidenciem nos trabalhos os caminhos metodológicos percorridos. Teve destaque positivo a coleta de dados multimétodos (questionários, entrevistas, questões-problema, produção de textos, fotografias etc.) 
A relação universidade-escola se apresenta como uma possibilidade de aquecer as discussões sobre tais práticas, trazendo um potencial transformador. Para os docentes presentes no GDP, esse vínculo nunca foi tão necessário, expondo uma demanda por ações conjuntas.

Dessa forma, a pesquisa se apresenta como uma possibilidade de aproximar IES e unidades escolares, mas com alguns cuidados que foram apontados na discussão do grupo. Destaca-se a necessidade de devolutiva às escolas dos produtos das pesquisas que, caso contrário, terminam engavetadas, seus resultados pouco divulgados, na perspectiva dos docentes.

A questão não é nova e poderia ser encarada como uma potência para ação transformadora. Considera-se que uma pesquisa em campo escolar traz sob o olhar analítico a exposição de orientações, práticas e resultados de uma situação particular - a escola pesquisada - trata-se de um zoom sobre aquela realidade. Nada poderia ser mais importante para uma escola do que a devolutiva de seus resultados. Trata-se de um compromisso político trazer essa devolutiva sob a forma de questões desafiadoras para debates que, espera-se, possibilitem avanços nas práticas docentes e na escola como um todo.

No atual momento que atravessamos, em termos de ameaças ao meio ambiente e aos direitos sociais como um todo, os esforços deveriam se voltar a construções coletivas com os docentes das escolas, que demandam por serem ouvidos nas pesquisas, desde a fase de elaboração. Essa seria uma ação compartilhada e, desde já, formativa também. Uma formação continuada em exercício que gera um produto de pesquisa em si, como fruto desse compartilhamento, e o que mais a pesquisa pretenda, além disso.

Uma perspectiva interessante, apontada pelos professores, foi a de pesquisas que se voltem aos professores egressos de formações específicas de EA, desde extensão, especialização ou mestrado, a fim de verificar o potencial transformador dessa formação em sua prática e na capacidade de envolver outros membros da escola. Os resultados podem remeter a um aprimoramento nos processos formativos e de pesquisa.

A expectativa dos docentes é que a pesquisa seja integradora, colaborativa e formativa, o que certamente traz o novo e coloca o trabalho em outro nível de relevância. Esse processo promove maior entrosamento entre pesquisador e pesquisado, com uma possibilidade de escuta do outro, necessária a qualquer processo reflexivo, como deve ser o da docência, e da transformação dos participantes. Dentre as possibilidades que a escola traz como elemento de adesão mais orgânica é o de envolvimento de toda a comunidade escolar. Dessa forma, pode ser dado conhecimento aos responsáveis pelos estudantes que, muitas vezes, desconhecem as ações que se dão na escola no campo da pesquisa e seus produtos.

As ações que gerem e sustentem a desejada integração com a escola podem ser incorporadas em projetos nas IES, a partir da curricularização da extensão, proposta pela Resolução 7/2018 CNE. Cabe, portanto, aos docentes das IES, demonstrar a urgência de incluir nas ações de curricularização a discussão das relações sociedade/natureza, dentre seus pontos estruturantes.

\subsection{Desenvolvimento da EA Crítica nas escolas}

Há a necessidade do estranhamento diante das relações assimétricas presentes na sociedade, que geram desigualdade e injustiças socioambientais. Seus cenários são naturalizados e passam a ser, por isso, invisibilizados. O próprio uso do território e o restrito direito à cidade por estudantes de escolas de periferia (NOVAES, 2017) é uma questão que passa a ser naturalizada e cuja aceitação se torna tácita.

É uma tarefa das práticas de EA Crítica escolar dar visibilidade à exposição a tais cenários, apontando os conflitos que explicam a realidade em questão. A problematização 
dessa realidade, quem são os atores envolvidos, quais interesses, quem são os agentes de dominação, quais forças os apoiam, são componentes que devem ser explicitados e contribuem para elucidar os determinantes dos quadros de injustiça socioambiental.

Como exemplo, o tema da água, tão frequente nas escolas, pode tratar de dar luz ao conceito do valão, sobre o qual a comunidade escolar se refere com naturalidade. Na maioria das vezes, trata-se de um rio que perdeu qualidade ao longo de processos de ocupação do território. Como se dá a qualidade de rios e águas em geral, em outras regiões mais privilegiadas da cidade? A questão vai remeter à oferta dos demais serviços públicos, diferentes em cada região da cidade, por exemplo. São caminhos que contribuem para evidenciar o papel do Estado, que aporta serviços e equipamentos em determinadas áreas da cidade, em detrimento de outras, evidenciando a injustiça ambiental.

Dessa forma, também se encaminha uma discussão pela desconstrução da ideia de ser humano genérico, associado ao território escolar, como uma primeira aproximação, mas que pode e deve ser ampliada para uma perspectiva global. Quando se fala de impactos socioambientais, serviços públicos em prol da qualidade de vida, certamente surge a oportunidade de distinção de grupos sociais, onde alguns são os beneficiados e outros são os prejudicados, alguns são os atores da destruição, outros são os afetados.

A naturalização das desigualdades produz e é produtora de impacto ambiental. Estabelecer relações socioambientais diante dos temas frequentes nas escolas não é tão óbvio e simples. Várias são as recomendações encontradas para que se desenvolvam, mas a dinâmica escolar pode ser pouco fértil para esse exercício.

Dentre alguns pontos necessários para essa explicitação destacam-se a necessidade de se discutir o que é desenvolvimento, fazendo a distinção entre crescimento econômico, que beneficia elites dominantes e o que deveria ser o desenvolvimento, aquele que deveria estar a serviço do avanço de conquistas e direitos crescentes para a maioria.

É fundamental que as ações de EA Crítica no contexto escolar, ou qualquer outro, visem à transformação da realidade e apontem para um cenário desejado, uma perspectiva que substitui a atual (TREIN, 2012), destruidora, concentradora de riqueza/geradora de desigualdade e de morte da vida. Essa perspectiva também apresenta o compromisso de apresentar possibilidades de transformação da atual organização desta sociedade, apresentando um discurso que mobiliza e aponta a esperança da superação.

A chamada questão ambiental ganhou cada vez maior dimensão nesse papel, com as recentes manifestações pela vida em encontros internacionais e ações de mobilização de juventude (SCHIERMEIER, 2019) e movimentos associados.

\section{Considerações finais}

As características dos artigos submetidos ao GDP-EA e contexto escolar de 2019 apresentam o padrão que pode ser comparado ao observado nos artigos do mesmo GDP de 2017, em que Silva e Domingos (2019) também apontaram o predomínio de professores e estudantes da escola básica como sujeitos pesquisados, a abordagem qualitativa como mais utilizada. Da mesma forma, são poucas as pesquisas que utilizam mais de instrumento para coleta de dados. Não obstante, em relação à análise de dados do último GDP, houve crescimento de artigos que identificam os referenciais teórico-metodológicos norteadores da análise de dados.

As diversas vertentes da EA no contexto escolar se encontram disseminadas nos artigos apresentados, o que indica que trabalhar com a EA cria espaços de integração entre as variedades de saberes e conhecimentos que permeiam os debates sobre os problemas socioambientais, em que a práxis pedagógica problematizadora, transformadora e libertadora é um contínuo desafio. 
As discussões do GDP trouxeram interessantes questões, apontando para a demanda, em particular de docentes da escola básica, por pesquisas mais compartilhadas e integradas entre pesquisadores e pesquisados, desde a fase de elaboração. Os docentes da escola básica propuseram ações de investigação conjunta, tornando-a colaborativa e formativa. Dessa forma, a pesquisa no contexto escolar se apresenta como uma possibilidade de aproximar IES e unidades escolares na construção de perspectivas de enfrentamentos de questões comuns.

Ao mesmo tempo, a devolutiva dos produtos das pesquisas às escolas foi reconhecida como possibilidade de contribuir para debates que permitam avanços nas práticas docentes e na escola como um todo.

\section{Referências}

ARAUJO, M. I. O.; DOMINGOS, P. Perspectiva teórico-metodológica da educação ambiental na escola. Pesquisa em Educação Ambiental, Rio Claro, v.13, n.1., p. 182-195, 2018.

AZEVEDO, L. F.; SILVA, S. N. Educação Ambiental na interface da Educação do Campo. IN: ENCONTRO PESQUISA EM EDUCAÇÃO AMBIENTAL, 8, 2015, Rio de Janeiro. Anais... Rio de Janeiro: UNIRIO/UFRJ, 2015. p.1-11. Disponível em: <http://epea.tmp.br/epea2015_anais/pdfs/plenary/179.pdf> Acesso em: 31 jan. 2020.

BARROS; A. J. P.; LEHFELD; N. A. S. Projeto de pesquisa: propostas metodológicas. Petrópolis: Vozes, 2014.

BOGDAN, R. C.; BIKLEN, S. K. Investigação Qualitativa em Educação: uma introdução à teoria e aos métodos. Lisboa: Porto Editora, 2004.

COSTA, C. A. S.; LOUREIRO, C. F. B. Educação ambiental crítica e interdisciplinaridade: a contribuição da dialética materialista na determinação conceitual. Terceiro Incluído, Goiânia, v.3, n.1, Jan./Jun., p. 1-22, 2013.

FIGUEIRA, M. R., LIMA, J. G. S.; SELLES, S. E. Educação ambiental crítica na relação universidade/escola: narrativas docentes. ENCONTRO PESQUISA DE EDUCAÇÃO AMBIENTAL, 9, 2017, Juiz de Fora. Anais... Juiz de Fora: UFJF, p.1-8, 2017. Disponível em: <http://epea.tmp.br/epea2017_anais/pdfs/plenary/0069.pdf>. Acesso em: 19 jan. 2018.

FREIRE, P. Pedagogia do oprimido. Rio de Janeiro: Paz e Terra, 2017.

FREIRE, P. Conscientização. São Paulo: Cortez, 2018.

GIL, A. C. Métodos e técnicas de pesquisa social. 6ed. São Paulo: Atlas, 2008.

GUIMARÃES, M. Armadilha paradigmática na educação ambiental. In: LOUREIRO, C. F. B.; LAYRARGUES, P. P. L.; CASTRO, R. S. de. (Orgs.). Pensamento complexo, dialética e educação ambiental. São Paulo: Cortez, 2006. p.15-29.

LAYRARGUES, P.P. O cinismo da reciclagem: o significado ideológico da reciclagem da lata de alumínio e suas implicações para a educação ambiental. In: LOUREIRO, C.F.B.; LAYRARGUES, P.P.; CASTRO, R. de S. (Orgs.) Educação ambiental: repensando o espaço da cidadania. São Paulo: Cortez. 2002. p. 179-219.

LAYRARGUES, P.P; LIMA. As macrotendências político-pedagógicas da Educação Ambiental brasileira. Ambiente \& Sociedade. São Paulo v. XVII, n. 1. p. 23-40, jan.-mar. 2014. 
LAMOSA, R. A. C. A educação ambiental e a nova pedagogia política do agronegócio. ENCONTRO PESQUISA DE EDUCAÇÃO AMBIENTAL, 9, 2017, Juiz de Fora. Anais... Juiz de Fora: UFJF, 2017. p.1-8. Disponível em: < http://epea.tmp.br/epea2017_anais/pdfs/plenary/0249.pdf> Acesso em: 25 jan. 2020.

LOUREIRO, C; B. F. Educação Ambiental: questões de vida. São Paulo: Cortez, 2019.

LOUREIRO, C. B. F.; LAYRARGUES, P. P. Ecologia política, justiça e educação ambiental crítica: perspectivas de aliança contra-hegemônica. Trab. Educ. Saúde, Rio de Janeiro, v. 11 n. 1, p. 53-71, jan./abr. 2013.

MORAES, R. GALIAZZI, M. C. Análise Textual Discursiva. 2 ed. Ijuí: Unijuí, 2011.

NOVAES, P. Gentrificação e o direito à cidade: o exemplo da cidade do Rio de Janeiro. In: SANTOS JUNIOR, O.A.; NOVAES, P.; LACERDA, L. E WERNECK, M. (Orgs.). Políticas públicas e direito à cidade: programa interdisciplinar de formação de agentes sociais. Rio de Janeiro: Letra Capital, 2017. p. 40-44.

PIZZANI, L. et al. A arte da pesquisa bibliográfica na busca do conhecimento. Revista Digital de Biblioteconomia e Ciência da Informação, Campinas, v.10, n.1, p.53-66, 2012.

ROSA, M.D., NOGUEIRA, M.L.S.L., SOUZA, J.P.T., ROCHA, P.N., PINK, J. e VIVERIO, A.A. As perspectivas de ambiente e de Educação Ambiental nos projetos de professores da Educação Básica em um curso de formação continuada. Ambiente \& Educação. Rio Grande, v.22, n. 2, p.88-108, 2017.

SANTOS. T. M.; SILVA, S. N. Educação Ambiental: problematização sobre agrotóxicos na formação inicial de professores a partir dos três momentos pedagógicos. In: Reunião de Estudos Ambientais REA, 8, 2018, Porto Alegre. Porto Alegre: UFRGS, 2018, p. 1-16. Disponível em: <https://www.dropbox.com/sh/pji8yq8t61 pu8ky/AABlANSWNFTaSqju9Q9j3z8Fa/ARTIGOS?dl=0 \&preview $=8$ REA107+-+Thais+Mendes+dos+Santos.pdf $>$ Acesso em: 20 jan. 2020.

SANTOS, C. J. et al. Pibid em uma escola do campo: uma proposta de educação ambiental para trabalhar problemas referentes às doenças hídricas. Revbea, São Paulo, v. 13, n. 1, 227-239, 2018.

SCHIERMEIER, Q. Greta Thunberg, climate catalyst. A Swedish teenager brought climate Science to the fore as she channelled her generation's rage. Nature, London, v.576, n.19/26 Dec, p. 372, Dec., 2019. Disponível em: <https://www.nature.com/immersive/d41586-019-03749-0/index.html> Acesso em: 25 jan. 2020.

SILVA, S. N. A BNCC da educação infantil ao ensino fundamental: políticas públicas currículo, competências e educação ambiental. Editora CRV: Curitiba, 2019.

SILVA, S. N.; DOMINGOS, P. Mapeamento dos artigos apresentados no grupo de discussão de pesquisa educação ambiental no contexto escolar no EPEA de 2017. Revista Sergipana de Educação Ambiental - REVISEA, São Cristóvão, v.7, n.2, p.73-82, 2019. Disponível em:

<https://seer.ufs.br/index.php/revisea/article/view/12845> Acesso em 25 jan. 2020.

SILVA, S. N.; EL-HANI, C. N. A abordagem do tema Ambiente e a formação do cidadão socioambientalmente responsável. Revista Brasileira de Pesquisa em Educação em Ciências, Belo Horizonte, v. 14, n. 2, p. 225- 234, 2014.

SPALAOR, F. A.; COSENZA, A. C. Problematizações Socioambientais: o que dizem os Projetos de Educação Ambiental elaborados e implementados por duas escolas da rede estadual de ensino pertencentes à jurisdição da SER/Juiz de Fora. In: ENCONTRO PESQUISA EM EDUCAÇÃO 
AMBIENTAL - EPEA, 9, 2017, Juiz de Fora. Anais... Juiz de Fora: UFJF, 2017. p.1-12. Disponível em: 〈http://epea.tmp.br/epea2017_anais/pdfs/plenary/0059.pdf> Acesso em 27 jul. 2018.

TOZONI-REIS, M. F. C. Temas ambientais como "temas geradores": contribuições para uma metodologia educativa ambiental crítica, transformadora e emancipatória. Educar, Curitiba, n. 27, p. 93-110, 2006.

TOZONI-REIS, M. F. C. Pesquisa-ação em Educação Ambiental. Pesquisa em Educação Ambiental, Rio Claro, v. 3, n. 1, p. 155-169, 2008.

TREIN, E. S. Educação ambiental crítica: crítica de quê? Revista Contemporânea de Educação, Rio de Janeiro, v. 7, n. 14, p. 304-318, Ago-Dez. 2012.

TUZZO, S. A; BRAGA, C. F. O processo de triangulação da pesquisa qualitativa: o metafenômeno como gênese. Revista Pesquisa Qualitativa, São Paulo, v.4, n.5, p.140-158, 2016. 